\title{
High Mitosis-Karyorrhexis Index
}

National Cancer Institute

\section{Source}

National Cancer Institute. High Mitosis-Karyorrhexis Index. NCI Thesaurus. Code

C118958.

An index used in neuroblastic tumors indicating the presence of more than 200 mitoses and karyorrhexis per 5,000 cells. 